\title{
COEFFICIENT ESTIMATES AND FEKETE-SZEGÖ INEQUALITY FOR NEW SUBCLASS OF BI-BAZILEVIČ FUNCTIONS BY $(s, t)$-DERIVATIVE OPERATOR AND QUASI-SUBORDINATION
}

\author{
AOEN*, ShuHAi Li AND HuO TANG
}

Abstract. In this paper we introduce and investigate a new generalized class of bi-bazilevič functions defined by using $(s, t)$-derivative operator and quasi-subordination in the open unit disk $\mathbb{D}$. We obtain two kinds of coefficient estimate by using Faber polynomial expansion and get Fekete-Szegö inequality for the new class and some of its subclasses.

Mathematics subject classification (2020): 30C45.

Keywords and phrases: bi-univalent function, bi-bazilevič function, $(s, t)$-derivative, quasi-subordination, coefficient estimate, Fekete-Szegö problem, Faber polynomial expansion.

\section{REFERENCES}

[1] M. S. Robertson, Quasi-subordination and coefficient conjectures, Bulletin of the American Mathematical Society 76, 1-9 (1970).

[2] S. Y. LEE, Quasi-subordinate functions and coefficient conjectures, Journal of the Korean Mathematical Society 12 (1), 43-50 (1975).

[3] F. Y. REN, S. OWA, S. FUKUI, Some inequalities on quasi-subordinate functions, Quasi-subordinate functions and coefficient conjecturesBulletin of the Australian Mathematical Society 43 (2), 317-324 (1991).

[4] M. M. Mohd, M. DARus, Fekete-Szegö problems for quasi-subordination classes, J. Abstract and Applied Analysis, Article ID.192956, 14 pages, doi:10.1155/2012/192956 (2012).

[5] B. SRutha, S. Prema, Coefficient problem for certain subclass of analytic functions using quasisubordination, J. Mathematics and Decision sciences 13 (6), 47-53 (2013).

[6] Amol B. Patil1, UdAy H. NAIK, Estimates on initial coefficients of certain subclasses of biunivalent functions associated with quasi-subordination, Global Journal of Mathematical Analysis, 5 (1), 6-10 (2017).

[7] S. P. Goyal, Onkar Singh, Rohit Mukherjee, Certain results on a subclass of analytic and bi-univalent functions associated with coefficient estimates and quasi-subordiantion, Palestine Journal of Mathematics 5 (1) (2016), 79-85.

[8] Ş. Altinkaya, S. Yalçın, Quasi-subordinations for certain subclasses of bi-univalent functions, Mathematical Advances in Pure and Applied Sciences 1 (2), 56-64 (2018).

[9] P. L. Duren, Univalent Functions, Grundlehren der Mathematischen Wissenschaften, vol. 259, Springer-Verlag, New York, 1983.

[10] M. LEwIN, On a coefficient problem for bi-univalent functions, Proc. Amer. Math. Soc. 18, 63-68 (1967).

[11] D. A. Brannan, J. G. Clunie, Aspects of contemporary complex analysis, In: Proceedings of the NATO Advanced Study Institute Held at the University of Durham, New York, NY, USA: Academic Press, 1980.

[12] E. Netanyahu, The minimal distance of the image boundary from the origin and the second coefficient of a univalent function in $|z|<1$, Arch. Rational Mech. Anal. 32, 100-112 (1969).

[13] A. W. KedZIERAWs Ki, Some remarks on bi-univalent functions, Ann Univ Mariae Curie-Sklodowska Sect A, 39, 77-81 (1985). 
[14] D. L. TAN, Coefficient estimates for bi-univalent functions, Chinese Ann Math Ser A, 5, 559-568 (1984).

[15] D. A. Brannan, T. S. Taha, On some classes of bi-univalent functions, In: Mazhar S. M., Hamoui A., Faour N. S., editors, KFAS Proceedings Series, Vol. 3. Oxford, UK: Pergamon Press, 53-60, 1988.

[16] H. M. Srivastava, A. K. Mishra, P. GochHayat, Certain subclasses of analytic and bi-univalent functions, Appl. Math. Lett., 23, 1188-1192 (2010).

[17] B. A. Frasin, M. K. Aouf, New subclasses of bi-univalent functions, Appl. Math. Lett. 24, 15691573 (2011).

[18] T. Hayami, S. Owa, Coefficient bound for bi-univalent functions, Pan Amer. Math. J. 22, 15-26 (2012).

[19] Q.-H. XU, H.-G. XiAO AND H. M. SRIVAStaVA, A certain general subclass of analytic and biunivalent functions and associated coefficient estimate problems, Appl. Math. Comput. 218, 1146111465 (2012).

[20] S. P. Goyal, P. Gos WAMI, Estimate for initial Maclaurin coefficients of bi-univalent functions for a class defined by fractional derivatives, J. Egyptian Math. Soc. 20, 179-182 (2012).

[21] El-Ashwah, Subclasses of bi-univalent functions defined by convolution, J. Egyptian Math. Soc. 22 (3), 348-351 (2014).

[22] S. Bulut, Coefficient estimates for a new subclass of analytic and bi-univalent functions, An. Stiint. Univ. Al. I. Cuza Iasi Mat. (N. S.) 62, 305-311 (2016).

[23] R. Vijaya, T. V. Sudharsan, S. Sivasubramaian, Coefficient estimates for certain subclasses of biunivalent functions defined by convolution, International Journal of Analysis, Article ID6958098, 5 pages (2016).

[24] A. Motamednezhad, Shahpour Nosrati, S. Zaker, Bounds for initial maclaurin coefficients of a subclass of bi-univalent functions associated with subordination, Commun. Fac. Sci. Univ. Ank. Ser. A1 Math. Stat. 68 (1), 125-135 (2019).

[25] P. Zaprawa, On the Fekete-Szegö problem for classes of bi-univalent functions, Bull. Belg. Math. Soc. Simon Stevin 21 (1), 169-178 (2014).

[26] Yalçn S. Altinkaya, The Fekete-Szegö problem for a general class of bi-univalent functions satisfying subordinate conditions, Sahand Communications in Mathematical Analysis, 5 (1), 1-7 (2017).

[27] J. M. Jahangiri, N. Magesh, J. Yamin, Fekete-Szegö inequalities for classes of bi-starlike and bi-convex functions, Electronic J. Math. Anal. Appl., 3 (1), 133-140 (2015).

[28] G. Saravanan, K. Muthunagai, Coefficient estimates and Fekete-Szegö inequality for a subclass of bi-univalent functions defined by symmetric q-derivative operator by using Faber Polynomial techniques, Periodicals of Engineering and Natural Sciences, 6 (1), 241-250 (2018).

[29] Ş. AltinkAYA, S. YALÇIN, Estimates on coefficients of a general subclass of bi-univalent functions associated with symmetric q-derivative operator by means of the chebyshev polynomials, Asia Pacific Journal of Math. 4 (2) 90-99 (2017).

[30] J. M. JAhANGIRL, S. G. HAMIDI, Coefficient estimates for certain classes of bi-univalent functions, Int. J. Math. Math. Sci. Article ID:190560, 1-4 (2013).

[31] J. M. JAhANGiRL, S. G. HAMidi, Advances on the coefficients of bi-prestarlike functions, C. R. Acad. Sci. Paris, Ser. I 354, 980-985 (2016).

[32] S. G. HAMidi, J. M.JAhANGIRI, Faber polynomial coefficients of bi-univalent functions defined by subordinations, Bull. Iran. Math. Soc., 41 (5), 1103-1119 (2015).

[33] Şahsene Altinkaya, Aibel Yalçin, On the Faber polynomial coefficient bounds of bi-bazilevibibazilevič functions functions, Commun. Fac. Sci. Univ. Ank. Series A1, 66 (2), 289-296 (2017).

[34] C. Ramachandran, D. KaVitha, Faber polynomial coefficient of bi-univalent functions with respect to symmetric q-derivative operator, International Journal of Pure and Applied Mathematics, 116 (2), 391-401 (2017).

[35] S. BUlut, Coefficient estimates for a subclass of analytic bi-univalent functions by means of Faber polynomial expansion, Palestine Journal of Mathmatics, 7 (1), 53-59 (2018).

[36] S. YalçIn, S. KHAN, S. HusS AIn, Faber polynomial coefficients estimates of bi-univalent functions associated with generalized Sălăgean q-differential operator, Konuralp Journal of Mathematics, 7 (1), 25-32 (2019).

[37] R. Chakrabarti, R. Jagannathan, $A(p, q)$-oscillator realization of two-parameter quantum algebras, J. Phys. A, 24, 711-718 (1991). 
[38] A. Motamednezhad, S. Salehian, New subclass of bi-univalent functions by $(p, q)$-derivative operator, Honan Mathematical J. 41 (2), 381-390 (2019).

[39] F. H. JACKSON, On q-functions and a certain difference operator, Trans. Roy. Soc. Edinburgh, 46, 253-281 (1908).

[40] H. Airault, A. Bouall, Differential calculus on the Faber polynomials, Bull. Sci. Math., 130 (3), 179-222 (2006).

[41] H. AIRAUlt, Remarks on Faber polynomials, Int. Math. Forum, 3 (9-12), 449-456 (2008).

[42] H. AirAult, JiAGANG REN, An algebra of differential operators and generating functions on the set of univalent functions, Bull. Sci. Math., 126 (5), 343-367 (2002).

[43] C. Pommerenke, Univalent functions, Vandenhoeck and Rupercht, Gottingen, 1975. 